
2
Noname manuscript No.

(will be inserted by the editor)

\section{An empirical comparison of asset-pricing models in the Shanghai A-share exchange market}

Received: date / Accepted: date

\begin{abstract}
This paper evaluates and compares the performance of three-asset pricing models- the capital asset pricing model of Sharpe (1964), the threefactor model of Fama and French (1993), and the five-factor model (Fama and French 2015)- in the Shanghai A-share exchange market. Our results do not support the superiority of the five-factor model and show that the three-factor model outperforms the other models. We also verify the redundancy of the book-to-market factor and confirm the findings of Fama and French (2015).
\end{abstract}

JEL classification $\mathrm{G} 1 \cdot \mathrm{C} 5$

Keywords Fama-French models · Capital asset pricing model - Shanghai exchange market

\section{Introduction}

Estimating the expected return on portfolios or the cost of equity for individual stocks has constantly been a central question in financial economics. For this purpose, three major asset-pricing models were created; the capital asset pricing model of Sharpe (1964), Lintner (1965) and Mossin (1966) (henceforth CAPM), the three-factor model (henceforth FF3FM) and the five-factor model (henceforth FF5FM) both developed by Fama and French in 1996 and 2015 respectively. For over thirty years, the CAPM has dominated the finance theory since it provides a simple and intuitive relation between systematic risk and return. However, the model has been subject to a lot of criticism reporting that the market beta coefficient alone cannot fully describe the cross-section of expected stock returns. For example, Banz (1981), Basu (1983), and Lakonishok, Shleifer, and Vishny (1994) found the existence of a relationship between average stock returns and firm size, book-to-market equity, earnings to price ratio, cash flow to price ratio and past sales growth. Following these studies 
among others, Fama and French $(1993,1996)$ constructed a three-factor model adding two factors to the market beta of the CAPM: the market capitalization and the book-to-market ratio.

On one hand, much empirical research demonstrates that the FF3FM outperforms the CAPM and describes well the cross-section of asset returns ((Griffin and Lemmon 2002); (Liew and Vassalou 2000)). On the other hand, many studies have shown anomalies left unexplained by the FF3FM and have discovered factors that seem to better explain average returns. For instance, Novy-Marx (2013) shows that profitable firms generate better returns than firms with low profitability. In the same way, Aharoni, Grundy, and Zeng (2013) find that there is a strong relationship between the investment factor and average returns. Based on these findings, Fama and French presented the five-factor model. In 2015, Fama and French expanded the FF3FM with two factors; profitability and investment. Compared to the CAPM and the FF3FM, the FF5FM achieve better results in describing the cross-section of stock returns using U.S data and international data from developed markets. Examples include Fama and French $(2015,2017)$. Although several studies have focused on the empirical testing of multifactor models in the developed markets, little attention has been given to Asian emerging markets. Chui and Wei (1998) were the first to examine the relationship between average stock returns and the market factor in the Asian region and validated the work of Fama and French (1996). They demonstrated that the market factor alone is not sufficient to describe the cross-section of expected returns and reported that average returns are closely related to book-to-market equity ratio and firm size. Additionally, Drew and Veeraraghavan $(2001,2002)$ found that the FF3FM performed better than the CAPM in the Shanghai Stock Exchange over the 1990s.

This paper has the following three objectives. First, we evaluate the performance of the FF5FM in the Shanghai stock market. Most studies have only focused on the empirical testing of this model in the developed and European emerging markets. For instance, Nichol and Dowling (2014) tested the FF5FM and confirmed its superiority over the FF3FM in the UK context. Particularly, they reported a strong profitability pattern and a weak investment effect in average returns. In Japan, Kubota and Takehara (2017) investigated the performance of the FF5FM and concluded that the addition of the profitability and investment factors did not significantly improve the description of average returns. In another major study, Zaremba and Czapkiewicz (2017) tested and compared the performance of four factor pricing models (the CAPM, the FF3FM, the FF5FM and the four-factor model of Carhart (1997)) in the European emerging stock markets and showed that the FF5FM is the least-bad model. Furthermore, Fama and French (2017) evaluated the explanatory power of size, value, profitability and investment in 23 developed countries and documented a positive relationship between average returns and profitability and a negative relation between average returns and investment. The only exception in their empirical research is Japan; they reported that the average returns of Japanese stocks have little relation with profitability and investment. This 
means that every region has its own anomalies and thus each market should be investigated specifically. Although these studies covered more than 30 different countries, very few studies focused on the evaluation of the performance of FF5FM in the Chinese market.Contrary to the developed markets, China is still emerging and thus represents an attractive context in which to study the asset pricing. In recent years, China has been making efforts to be one of the global markets by opening more segments to foreign investors. In 2015, China's foreign direct investment reached $\$ 118$ billion and is expected to increase by $15 \%$ in 2017 due to reducing restrictive measures on foreign investment. Yet, market imperfections such as the lack of transparency and weak market discipline still exist in the Chinese market. This makes the empirical investigation into the Chinese stock market important. The central question that arises in this paper is whether the superiority of the FF5FM is a phenomenon only related to the developed markets. In view of market inefficiencies that has been mentioned so far, one would anticipate higher returns on Chinese stock market anomalies. In an analysis of the explanatory power of profitability and investment in the Chinese market, Lin (2017) verified the superiority of the FF5FM over the FF3FM, documented a strong profitability pattern and found a weak investment effect in average stock returns. In another similar study, Guo et al (2017) provided an out-of-sample test of the FF5FM in the Chinese stock market and found results consistent with Fama and French (2015) and Lin (2017). In addition, they showed that the investment factor shows little relation with average stock returns. Both studies use the ratio of operating profits as a proxy for profitability in the FF5FM. In this paper, we adopt a slightly different approach; we replace the profitability proxy of Fama and French by the net profit before tax over the total shareholders equity. According to Hou et al (2015), this proxy generates higher returns than that used in Fama and French (2015). To our knowledge, no study to date has ever assessed the performance of the FF5FM with a modified profitability proxy. By doing so, our research contributes to extending the literature on asset pricing in the Chinese equity market. Second, to search for a better asset-pricing model, we compare factor-pricing models (CAPM, FF3FM and FF5FM) in explaining average returns. We use standard asset-pricing tests (adjusted R2, average absolute of the intercepts and the GRS statistic) and include the GMM J-based statistic following MacKinlay and Richardson (1991) and Cochrane (2005). Commenting on the theoretical background of their multifactor model, Fama and French (2017) argued that "given their flimsy theoretical underpinnings, empirical asset pricing models can be judged only on empirical robustness". We follow the same rationale in our study. Third, Fama and French (2015) find that the book-to-market factor becomes redundant when profitability and investment are included. Our final goal is to investigate the redundancy of the value factor in the Shanghai equity market.

The findings of this study can be summarized as follows. The FF3FM outperforms the CAPM and the FF5FM in explaining average stock returns. In addition, we find that the book-to-market factor is redundant when the profitability and investment factors are present, which is line with the findings 
of Fama and French (2015). Moreover, we find that the FF5FM without the book-to-market factor performs better than the FF5FM in the Shanghai stock market.

The organization of the remainder of the paper is as follows. Section 2 presents a literature review. Section 3 outlines the data and portfolio construction method. Empirical findings are discussed in section 4 with section 5 presenting concluding comments.

\section{Literature review}

A considerable amount of literature has confirmed the relationship between average returns, firm size and book-to-market ratio (Banz, 1981; Basu, 1983, Fama and French, 1992). Following these studies, Fama and French (1993) constructed a three-factor model by augmenting the CAPM with two additional factors; size and book-to-market ratio. Later in 1996, Fama and French conducted an empirical testing using data from developed markets and showed that the FF3FM outperforms the CAPM in explaining the cross-section of average stock returns. In China, numerous studies have followed the previous approach and considered the FF3FM as a benchmark model. For instance, Chui and Wei (1998), and Xie and Qu (2016) report that size and value premiums are significant. However, these studies provide mixed results and show that many anomalies are still left unexplained by the FF3FM. Attempting to uncover those anomalies, Novy-Marx (2013) and Haugen and Baker (1996) find a positive relationship between average stock returns and profitability and Titman et al. (2004) report that average stock returns are negatively associated with investment. Motivated by the recent findings on the effects of the profitability and investment factors on stock returns, Fama and French (2015) constructed a five-factor model adding two new factors associated to profitability and investment. In 2017, they conducted a comprehensive empirical testing of this model and showed that the FF5FM outperforms the FF3FM in explaining average stock returns. Similarly, Nichol and Dowling (2017) evaluate the performance of the FF5FM in the UK and find results consistent with the findings of Fama and French (2017).

In China, only two studies are relevant to our research. Lin (2017) investigates the explanatory power of the profitability and investment ratios over the period 1997-2015 and supports the superiority of the FF5FM. In the same way, Guo et al (2017) test the FF5FM and report a strong effect of size and profitability and a weak investment pattern. They also find that the investment factor is redundant which contradicts the results of Fama and French (2015, 2017). Both studies follow the methodology of Fama and French in constructing factors related to size, value, profitability, and investment.

Our study has several contributions. First, we test the FF5FM in the Shanghai stock market and follow Fama and French approach in constructing factors associated with size, value, and investment. However, regarding the profitability factor, we use the net profit before tax over the total shareholders 
equity. This proxy is recommended by Hou et al (2015) and is shown to generate higher returns than that of Fama and French. As far as we know, there are no studies that investigate the performance of the FF5FM using a different profitability proxy. Therefore, our study adds to the asset-pricing literature. Our second goal is to compare the factor pricing models (CAPM, FF3FM, FF5FM) and look for the best model for pricing Chinese equities. Last but not least, we examine the redundancy of the value factor in the FF5FM. The main findings of this study can be summarized as follows: the FF3FM performs better than both the CAPM and the FF5FM. This result contradicts the previous research (Fama and French (2015, 2017), Lin (2017), Guo et al (2017)), which supports the superiority of the FF5FM. A significant profitability effect and a weak investment pattern are observed in our sample, which is in line with the findings of the precedent studies. However, we find that the value factor is redundant in the FF5FM in the Shanghai equity market, which contradicts the results of Lin (2017) and Guo et (2017) who report a redundancy of the investment factor in the Chinese stock market.

\section{Data and methodology}

This study uses stocks traded on the Shanghai A-Share Exchange Market. The main data source is Datastream. According to Bartholdy and Peare (2005), the market beta values of the CAPM are sensitive to data frequency and period. They found that weekly or daily stock data do not provide a good estimation of beta. In addition, the beta values can become bias if the research period is long. Hence, our accounting data includes monthly-adjusted closing prices and monthly returns on Shanghai A-share index and our sample period is short and extends from January 2011 to December 2016.

We first begin by testing the CAPM. Our regression model is:

$\mathrm{R}_{i}(\mathrm{t})=\mathrm{a}_{i}+\mathrm{b}_{i}\left(\mathrm{R}_{m}(\mathrm{t})-\mathrm{R}_{f}(\mathrm{t})\right)+\mathrm{e}_{i}(\mathrm{t})$

Secondly, we test the FF3FM using the following equation:

$\mathrm{R}_{i}(\mathrm{t})=\mathrm{a}_{i}+\mathrm{b}_{i}\left(\mathrm{R}_{m}(\mathrm{t})-\mathrm{R}_{f}(\mathrm{t})\right)+\mathrm{s}_{i} \mathrm{SMB}(\mathrm{t})+\mathrm{h}_{i} \mathrm{HML}(\mathrm{t})+\mathrm{e}_{i}(\mathrm{t})$

Finally yet importantly, we examine the FF5FM using the following regression equation:

$\mathrm{R}_{i}(\mathrm{t})=\mathrm{a}_{i}+\mathrm{b}_{i}\left(\mathrm{R}_{m}(\mathrm{t})-\mathrm{R}_{f}(\mathrm{t})\right)+\mathrm{s}_{i} \mathrm{SMB}(\mathrm{t})+\mathrm{h}_{i} \mathrm{HML}(\mathrm{t})+\mathrm{p}_{i} \mathrm{RMW}(\mathrm{t})+\mathrm{l}_{i} \mathrm{CMA}(\mathrm{t})$ $+\mathrm{e}_{i}(\mathrm{t})$

Where $\mathrm{R}_{i}(\mathrm{t})$ is the monthly excess return on a certain portfolio $\mathrm{i}$ for month $\mathrm{t}$ and $\mathrm{R}_{m}(\mathrm{t})$ is the monthly return on the Shanghai A-share index. $\mathrm{R}_{f}(\mathrm{t})$ is the return on the one-month interest rate. In China, the one-month interest rate is unavailable and replaced with the three-month interest rate divided by three. SMB represents the difference each month between the returns of the three small market capitalization portfolios and the returns of the three big market capitalization portfolios. HML is the difference each month between the returns of the two high book-to-market portfolios and the returns of the two low book-to-market portfolios. RMW and CMA are calculated the same way as HML sorted by profitability and investment respectively. The factor 
loadings for each variable are $\mathrm{b}_{i}, \mathrm{~s}_{i}, \mathrm{~h}_{i}, \mathrm{p}_{i}$ and $\mathrm{l}_{i}$. $\mathrm{e}_{i}(\mathrm{t})$ represents the error term.

In order to construct the factors used in the three models cited above, we need measures of book-to-equity, profitability and investment ratios. According to Fama and French (1993), we exclude companies with negative book-tomarket ratios. Following Fama and French (2008, 2015), we use asset growth as a proxy for investment, which is calculated as Total Assets T $_{t-1}$ minus Total Assets $_{t-2}$, dividing the result by Total Assets A $_{t-2}$.

To measure profitability, we use return on equity defined as the net profit before tax in year t by the total shareholder's equity in the same year. This is strongly recommended by Hou et al $(2015,2017)$. They show that this proxy generates higher returns than the proxy used by Fama and French (2015).

We start by forming portfolios at the end of December at year $t$. The sorting process begins by defining yearly breakpoints for size, book-to-market, profitability and investment ratios. The yearly market capitalization median is used as the breakpoint for size. This is strongly advocated by Fama and French (2015). For all other factors, the yearly sample $30^{\text {th }}$ and $70^{\text {th }}$ percentiles are used as breakpoints in the sorting method. Having obtained the breakpoints, we form six portfolios from the intersection of two size and three book-to-market portfolios. Monthly value-weighted returns on each of these six portfolios are calculated from January to December of year $t+1$. SMB and HML that capture the returns associated with size and book-to-market are then calculated. RMW and CMA are calculated in the same way by forming two size groups and three groups of profitability and investment factors respectively.

Panel A of Table 1 presents the summary statistics for the asset pricing factors used in the study. SMB is the only factor that generates a significantly positive return. The returns on RMW and CMA are positive but statistically insignificant. Panel B shows the correlation between asset pricing factors. HML, RMW and CMA are all negatively correlated with the size factor. The only surprising result is the relationship between HML and CMA. Fama and French (2015) report a positive correlation but our results show that these two factors are negatively correlated.

Table 2 shows the average excess returns for the six portfolios. In each panel, we observe a size effect; the small stocks have higher average returns than big stocks. This finding supports the significant SMB return in Table 1. In Panel A, the value effect is only significant across the big stocks; average monthly returns rise from $-0.31 \%$ for the lowest book-to-market portfolios to $-0.09 \%$ for the highest book-to-market portfolios. The relationship between average returns and the profitability, called the profitability effect, shows up more consistently in Panel B. For every size row, high profitability portfolios have higher average excess returns than the lowest profitability portfolios. Panel $\mathrm{C}$ of Table 2 shows the relationship between excess returns and the investment. For big portfolios, low asset growth stocks outperform high asset growth stocks. 
Table 1: Summary statistics for factor returns; January 2011 to December 2016

\begin{tabular}{|c|c|c|c|c|c|}
\hline & $\mathrm{R}_{m}-\mathrm{R}_{f}$ & SMB & HML & RMW & CMA \\
\hline \multicolumn{6}{|c|}{ Panel A: Summary statistics } \\
\hline Mean & -0.66 & 1.11 & -0.10 & 0.18 & 0.05 \\
\hline Std dev & 7.23 & 3.40 & 3.36 & 2.21 & 1.42 \\
\hline t-Mean & -0.78 & 2.75 & -0.25 & 0.70 & 0.32 \\
\hline \multicolumn{6}{|c|}{ Panel B: Correlation coefficients } \\
\hline $\mathrm{R}_{m}-\mathrm{R}_{f}$ & 1 & & & & \\
\hline SMB & -0.02 & 1 & & & \\
\hline HML & -0.01 & -0.49 & 1 & & \\
\hline RMW & -0.16 & -0.51 & 0.08 & 1 & \\
\hline CMA & 0.03 & -0.15 & -0.34 & 0.46 & 1 \\
\hline
\end{tabular}

Table 2: Average monthly excess returns for portfolios formed on size and book-to-market, size and profitability, and size and asset growth

\begin{tabular}{|c|c|c|c|}
\hline & Low & Medium & High \\
\hline \multicolumn{4}{|c|}{ Panel A: size/book-to market portfolios } \\
\hline Small & 1.02 & 0.87 & 0.60 \\
\hline Big & -0.31 & -0.24 & -0.09 \\
\hline \multicolumn{4}{|c|}{ Panel B: size/profitability portfolios } \\
\hline Small & 0.97 & 0.75 & 1.08 \\
\hline Big & -0.42 & -0.13 & -0.17 \\
\hline \multicolumn{4}{|c|}{ Panel C: size/investment portfolios } \\
\hline Small & 1.00 & 0.80 & 0.88 \\
\hline Big & -0.29 & -0.27 & -0.06 \\
\hline
\end{tabular}

\section{Results}

The aim of this research is to evaluate and compare the performance of three asset-pricing models: the CAPM, the FF3FM, and the FF5FM. First, we examine the regression coefficients of each model to assess the explanatory power of the market, size, profitability, and investment factors. Second, to compare our models, we use the F statistic of Gibbons, Ross and Shanken (GRS, 1989) to test the zero intercept hypothesis. The GRS test assumes that stock returns are identically, independently, and normally distributed. However, since this assumption is not always true, we add to our tests the GMM J-statistic on the regression intercepts following MacKinlay and Richardson (1991) and Cochrane (2005). In addition, we report the average absolute intercept (ABS(a)), the average adjusted $\mathrm{R}^{2}$ and the average standard error of the intercepts $(\mathrm{SE}(\mathrm{a}))$.

\subsection{Portfolios formed on size and book-to-market}

Table 3 reports the regression coefficients for the six size and book-tomarket portfolios. For every asset-pricing model, we report the intercepts, 
the factor loadings on each factor, and the adjusted $\mathrm{R}^{2}$. Panel $\mathrm{A}$ shows the regression results for the CAPM. The market factor loadings are all significant at the $1 \%$ level and four out of six intercepts are distinguishable from zero. In Panel B, the results for the FF3FM are presented. The regression intercepts are all indistinguishable from zero showing that the FF3FM outperforms the CAPM in explaining average returns. In addition, the loadings (s) on the SMB factor are all dramatically significant at the $1 \%$ level indicating that our results are consistent with the findings of Fama and French (1996). The small capitalization portfolios have positive slopes on SMB while big portfolios have diminishing positive slopes. Regarding the HML factor loadings, five out of six are significant at the $10 \%$ confidence level. Panel $\mathrm{C}$ shows the results for the FF5FM. RMW is significant for all six portfolios at the $10 \%$ level. However, for the CMA factor, only one out of six is significant. Overall, Table 3 shows that the average adjusted $\mathrm{R}^{2}$ for the CAPM is only 0.74 while it is around 0.93 for both the FF3FM and the FF5FM. This result supports the superiority of the FF3FM and the FF5FM over the CAPM in explaining average returns. However, the FF3FM and the FF5FM perform similarly in explaining returns for the six size and book-to-market portfolios.

\subsection{Portfolios formed on size and investment}

We now report the regressions for the six portfolios formed on size and investment. Panel A of Table 4 shows that the intercepts are not close to zero which is sufficient to conclude that the CAPM does not explain well average stock returns. As we can see in Table 4, all of the six size and investment portfolios load positively and significantly on the market factor. In Panel B, we observe that the FF3FM intercepts are all close to zero and factors are mostly significant. Panel C provides regression details for the FF5FM. We observe that there is no clear pattern in the HML slopes. However, there is a clear relationship between investment and expected returns; average returns are positive for high investment portfolios and negative for low investment portfolios. This result contradicts the findings of Fama and French (2015). The average adjusted $\mathrm{R}^{2}$ is 0.76 for the CAPM, 0.93 for the FF3FM, and 0.94 for the FF5FM. This result confirms that both the FF3FM and the FF5FM explain average stock returns better than the CAPM. Nonetheless, based only on the adjusted $\mathrm{R}^{2}$, we cannot confirm which of the FF3FM or the FF5FM is the preferred model.

\subsection{Portfolios formed on size and profitability}

In Table 5, we show the regression details for the portfolios formed on size and profitability. As shown in Panel A, the CAPM intercepts are mostly close to zero indicating that the CAPM cannot capture all the variations in average returns for size and profitability portfolios. Panel B reports the results for the 
Table 3: Regressions for six size/book-to-market portfolios

\begin{tabular}{|c|c|c|c|c|c|c|}
\hline \multicolumn{7}{|c|}{ Size/Book-To-Market } \\
\hline & Low & Medium & High & Low & Medium & High \\
\hline \multicolumn{7}{|c|}{ Panel $A$ : the $C A P M$} \\
\hline \multicolumn{4}{|c|}{ a } & \multicolumn{3}{|c|}{$\mathrm{t}(\mathrm{a})$} \\
\hline Small & 1.75 & 1.61 & 1.33 & $2.34^{*}$ & $2.31^{*}$ & $2.20^{*}$ \\
\hline \multirow[t]{2}{*}{ Big } & 0.41 & 0.52 & 0.63 & 0.68 & 1.20 & $2.47^{*}$ \\
\hline & \multicolumn{3}{|c|}{$\mathrm{b}$} & \multicolumn{3}{|c|}{$\mathrm{t}(\mathrm{b})$} \\
\hline Small & 1.11 & 1.12 & 1.11 & $10.69 * * *$ & $11.60 * * *$ & $13.26^{* * *}$ \\
\hline \multirow[t]{2}{*}{ Big } & 1.10 & 1.16 & 1.09 & $13.09 * * *$ & $19.18^{* * *}$ & $30.83^{* * *}$ \\
\hline & \multicolumn{3}{|c|}{ Adjusted $\mathrm{R}^{2}$} & & & \\
\hline Small & 0.61 & 0.65 & 0.71 & & & \\
\hline Big & 0.71 & 0.84 & 0.93 & & & \\
\hline \multicolumn{7}{|c|}{ Panel B: the FF3FM } \\
\hline \multicolumn{4}{|c|}{ a } & \multicolumn{3}{|c|}{$\mathrm{t}(\mathrm{a})$} \\
\hline Small & 0.25 & 0.23 & -0.03 & 0.96 & 0.69 & -0.08 \\
\hline \multirow[t]{2}{*}{ Big } & 0.11 & 0.15 & 0.40 & 0.34 & 0.47 & 1.54 \\
\hline & \multicolumn{3}{|c|}{$\mathrm{b}$} & \multicolumn{3}{|c|}{$\mathrm{t}(\mathrm{b})$} \\
\hline Small & 1.12 & 1.13 & 1.13 & $32.52^{* * *}$ & $26.06^{* * *}$ & $25.66^{* * *}$ \\
\hline \multirow[t]{2}{*}{ Big } & 1.10 & 1.16 & 1.09 & $24.97 * * *$ & $28.12^{* * *}$ & $32.41^{* * *}$ \\
\hline & \multicolumn{3}{|c|}{$\mathrm{s}$} & \multicolumn{3}{|c|}{$\mathrm{t}(\mathrm{s})$} \\
\hline Small & 1.30 & 1.21 & 1.23 & $15.45^{* * *}$ & $11.42^{* * *}$ & $11.48^{* * *}$ \\
\hline \multirow[t]{2}{*}{ Big } & 0.16 & 0.29 & 0.23 & 1.50 & $2.83^{* *}$ & $2.80 * *$ \\
\hline & \multicolumn{3}{|c|}{$\mathrm{h}$} & \multicolumn{3}{|c|}{$\mathrm{t}(\mathrm{h})$} \\
\hline Small & -0.70 & -0.53 & -0.10 & $-8.18^{* * *}$ & $-4.99 * * *$ & -0.92 \\
\hline Big & -1.21 & -0.62 & 0.19 & $-11.14^{* * *}$ & $-6.12^{* * *}$ & $2.30^{*}$ \\
\hline & & djusted $R^{2}$ & & & & \\
\hline Small & 0.96 & 0.93 & 0.92 & & & \\
\hline Big & 0.92 & 0.92 & 0.94 & & & \\
\hline Panel & : the $F$ & $5 F M$ & & & & \\
\hline & & $\mathrm{a}$ & & & & (a) \\
\hline Small & 0.49 & 0.44 & 0.23 & $1.85^{*}$ & 1.33 & 0.72 \\
\hline Big & 0.31 & 0.33 & 0.57 & 0.94 & 1.03 & 2.15 \\
\hline & & $\mathrm{b}$ & & & & (b) \\
\hline Small & 1.10 & 1.10 & 1.09 & $32.52^{* * *}$ & $25.60^{* * *}$ & $25.89^{* * *}$ \\
\hline Big & 1.06 & 1.13 & 1.07 & $24.81^{* * *}$ & $27.50^{* * *}$ & $31.64^{* * *}$ \\
\hline & & $\mathrm{s}$ & & & & (s) \\
\hline Small & 1.14 & 1.06 & 1.05 & $11.71^{* * *}$ & $8.62^{* * *}$ & $8.73^{* * *}$ \\
\hline Big & 0.03 & 0.16 & 0.11 & 0.24 & 1.38 & 1.15 \\
\hline & & $\mathrm{h}$ & & & & h) \\
\hline Small & -0.76 & -0.53 & -0.08 & $-8.21 * * *$ & $-4.52^{* * *}$ & -0.73 \\
\hline Big & -1.17 & -0.61 & 0.16 & $-9.98 * * *$ & $-5.45^{* * *}$ & $1.70^{*}$ \\
\hline & & $\mathrm{r}$ & & & & (r) \\
\hline Small & -0.40 & -0.50 & -0.64 & $-2.77^{* *}$ & $-2.76^{* *}$ & $-3.56^{* * *}$ \\
\hline Big & -0.56 & -0.44 & -0.32 & $-3.05 * *$ & $-2.53^{*}$ & $-2.20^{*}$ \\
\hline & & $\mathrm{c}$ & & & & (c) \\
\hline Small & 0.00 & 0.35 & 0.49 & -0.01 & 1.31 & $1.84^{*}$ \\
\hline Big & 0.55 & 0.34 & 0.06 & $2.03^{*}$ & 1.31 & 0.29 \\
\hline & & djusted $R^{2}$ & & & & \\
\hline Small & 0.96 & 0.94 & 0.93 & & & \\
\hline Big & 0.93 & 0.93 & 0.94 & & & \\
\hline
\end{tabular}

This table shows the regression details for the six size/book-to-market portfolios for December 2011 January 2016. The regressions use the CAPM, the FF3FM, and the FF5FM to explain average returns. The table reports the intercepts, the coefficients for each factor, and the adjusted $\mathrm{R} 2$. The results are expressed in percentages. $* * *, * *, *$ denote significance at the $1 \%, 5 \%$, and $10 \%$ levels, respectively. 
Table 4: Regressions for six size/investment portfolios

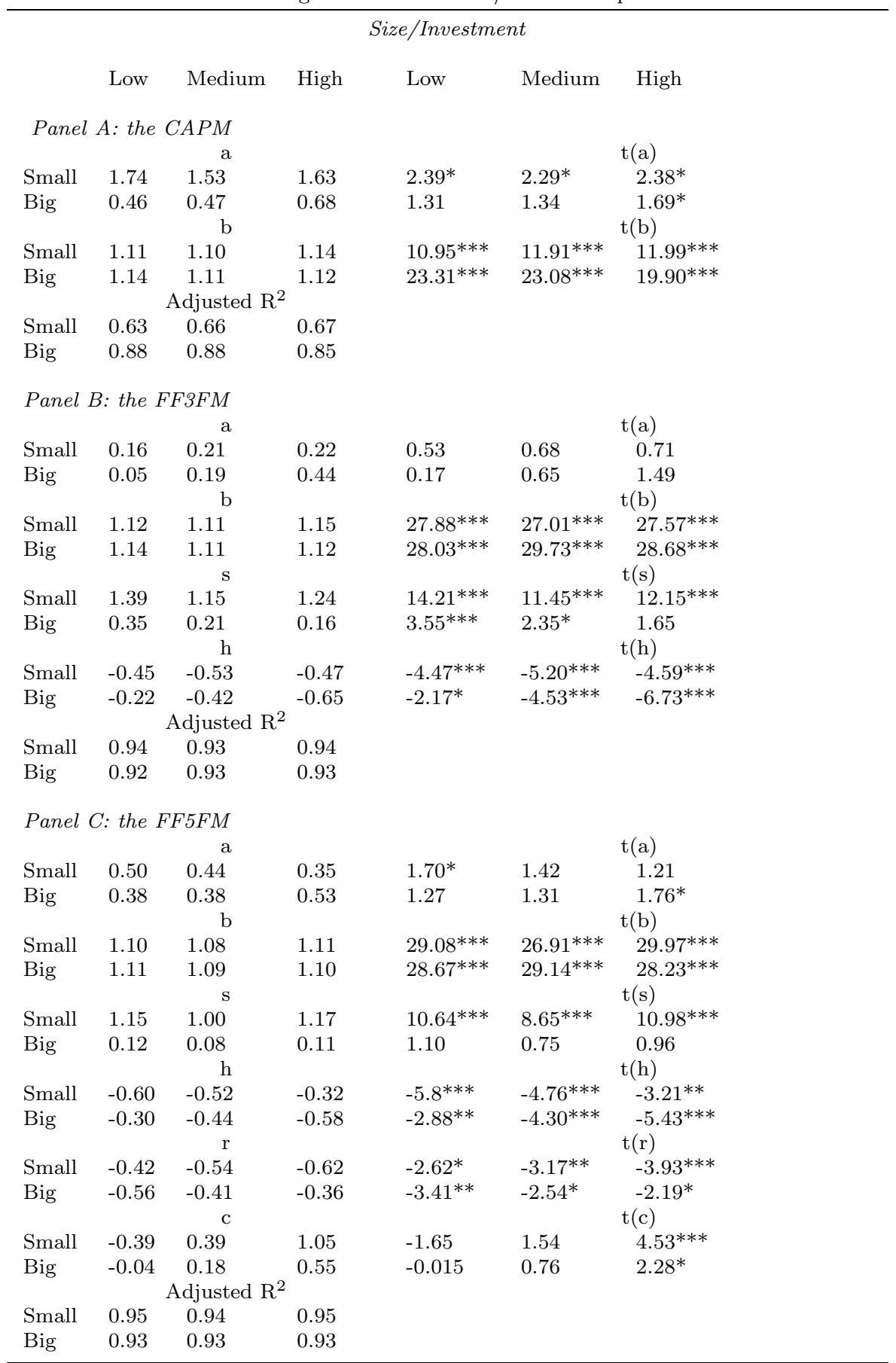

This table shows the regression details for the six size/investment portfolios for December 2011 January 2016. The regressions use the CAPM, the FF3FM, and the FF5FM to explain average returns. The table reports the intercepts, the coefficients for each factor, and the adjusted R2. The results are expressed in percentages. $* * *, * *, *$ denote significance at the $1 \%, 5 \%$, and $10 \%$ levels, respectively. 
FF3FM. We notice that there is a considerable improvement compared with the CAPM, as only two out of six regression intercepts are significant. This finding suggests that the market factor along with HML and SMB capture variations in average returns better than the CAPM. We also observe a size pattern; the SMB slopes increase from strongly positive for small stocks to slightly positive for big stocks. However, there is no clear pattern for HML slopes. In Panel C, RMW slopes increase from strongly negative for low profitability portfolios to weakly negative or slightly positive for high profitability portfolios. Looking at CMA slopes, only two out of six are significant at the $10 \%$ level. Hence, the investment factor has little impact on portfolios formed on profitability. The average adjusted $\mathrm{R}^{2}$ is 0.75 for the CAPM, 0.93 for the FF3FM, and 0.94 for the FF5FM suggesting that the latter two models outperform the CAPM.

As shown in this section, our results were quite expected. We observe strong size, value and profitability effects. However, the investment pattern is weak. This result is consistent with the findings of Fama and French $(2015,2017)$, Lin (2017) and Guo et al (2017).

\subsection{Comparison of the asset-pricing models}

In this section, we provide additional tests to compare the asset-pricing models. We report the GRS tests statistics, the GMM J statistics, the average adjusted $\mathrm{R}^{2}$, the average absolute value of the intercepts $\mathrm{ABS}(\mathrm{a})$, and the average standard error of the intercepts SE(a). Panel A of Table 6 reports the test statistics for the CAPM. As can be seen, the CAPM performs poorly and is rejected at the $10 \%$ level in our tests. The GRS statistics are between 4.44 and 4.68 and the J statistics are between 3.73 and 3.93. Switching to the FF3FM, we observe a significant improvement in our statistics suggesting that adding the size and value factors improve the description of average returns. The GRS statistics decrease and range between 0.52 and 0.63. Clearly, the FF3FM has no difficulty in explaining the portfolios formed on size and value, investment and profitability factors respectively. Interestingly, the FF3FM performs better than the FF5FM suggesting that one of the five factors might be redundant. This finding contradicts the results of Fama and French (2015) who report the superiority of the five-factor model. Moreover, Fama and French (2015) find that the value factor is redundant in the US; while Lin (2017) and Guo et al (2017) show that the CMA factor is redundant in the Chinese market. In the next section, we empirically test whether HML is redundant in the Shanghai equity market and compare the FF5FM without the HML factor with the previous models (CAPM, FF3FM and FF5FM). 
Table 5: Regressions for six size/profitability portfolios

\begin{tabular}{|c|c|c|c|c|c|c|}
\hline \multicolumn{7}{|c|}{ Size/Profitability } \\
\hline & Low & Medium & High & Low & Medium & High \\
\hline \multicolumn{7}{|c|}{ Panel A: the CAPM } \\
\hline & & $\mathrm{a}$ & & & & $\mathrm{t}(\mathrm{a})$ \\
\hline Small & 1.71 & 1.48 & 1.80 & $2.33^{*}$ & $2.16^{*}$ & $2.80^{* *}$ \\
\hline Big & 0.34 & $\begin{array}{r}0.63 \\
\mathrm{~b}\end{array}$ & 0.55 & 0.74 & 1.55 & $\begin{array}{l}1.68^{*} \\
\mathrm{t}(\mathrm{b})\end{array}$ \\
\hline Small & 1.12 & 1.10 & 1.10 & $10.97^{* * *}$ & $11.63^{* * *}$ & $12.32^{* * *}$ \\
\hline \multirow{2}{*}{\multicolumn{7}{|c|}{ Adjusted $\mathrm{R}^{2}$}} \\
\hline & & & & & & \\
\hline Small & 0.63 & 0.65 & 0.68 & & & \\
\hline Big & 0.82 & 0.85 & 0.89 & & & \\
\hline \multicolumn{7}{|c|}{ Panel B: the FF3FM } \\
\hline & & $\mathrm{a}$ & & & & $\mathrm{t}(\mathrm{a})$ \\
\hline Small & 0.12 & 0.12 & 0.52 & 0.36 & 0.40 & $1.69^{*}$ \\
\hline Big & -0.28 & $\begin{array}{r}0.27 \\
\mathrm{~b}\end{array}$ & 0.49 & -0.73 & 0.87 & $\begin{array}{l}1.74^{*} \\
\mathrm{t}(\mathrm{b})\end{array}$ \\
\hline Small & 1.13 & 1.11 & 1.11 & $25.65^{* * *}$ & $28.22^{* * *}$ & $27.87^{* * *}$ \\
\hline Big & 1.16 & $\begin{array}{r}1.15 \\
\mathrm{~s}\end{array}$ & 1.07 & $22.99^{* * *}$ & $29.03^{* * *}$ & $\begin{array}{l}29.33^{* * *} \\
\mathrm{t}(\mathrm{s})\end{array}$ \\
\hline Small & 1.41 & 1.18 & 1.13 & $13.10^{* * *}$ & $12.26^{* * *}$ & $11.59^{* * *}$ \\
\hline Big & 0.54 & $\begin{array}{r}0.28 \\
\mathrm{~h}\end{array}$ & 0.01 & $4.38^{* * *}$ & $2.92^{* *}$ & $\begin{array}{l}0.09 \\
\mathrm{t}(\mathrm{h})\end{array}$ \\
\hline Small & -0.40 & -0.57 & -0.49 & $-3.66^{* * *}$ & $-5.86^{* * *}$ & $-4.94^{* * *}$ \\
\hline \multirow[t]{2}{*}{ Big } & -0.27 & -0.55 & -0.49 & $-2.16^{*}$ & $-5.58^{* * *}$ & $-5.37 * * *$ \\
\hline & & Adjusted $\mathrm{R}^{2}$ & & & & \\
\hline Small & 0.93 & 0.94 & 0.94 & & & \\
\hline Big & 0.89 & 0.93 & 0.93 & & & \\
\hline \multicolumn{7}{|c|}{ Panel $C$ : the FF5FM } \\
\hline & & $\mathrm{a}$ & & & & $\mathrm{t}(\mathrm{a})$ \\
\hline Small & 0.58 & 0.29 & 0.43 & $1.96^{*}$ & 0.96 & 1.33 \\
\hline Big & 0.32 & $\begin{array}{r}0.45 \\
\mathrm{~b}\end{array}$ & 0.48 & 0.99 & 1.48 & $\begin{array}{l}1.61 \\
\mathrm{t}(\mathrm{b})\end{array}$ \\
\hline Small & 1.09 & 1.09 & 1.12 & $28.19^{* * *}$ & $28.01^{* * *}$ & $27.01^{* * *}$ \\
\hline Big & 1.10 & $\begin{array}{r}1.13 \\
\mathrm{~s}\end{array}$ & 1.07 & $26.73^{* * *}$ & $28.80^{* * *}$ & $\begin{array}{l}28.03^{* * *} \\
\mathrm{t}(\mathrm{s})\end{array}$ \\
\hline Small & 1.09 & 1.07 & 1.19 & $9.82^{* * *}$ & $9.63^{* * *}$ & $10.00^{* * *}$ \\
\hline Big & 0.12 & $\begin{array}{r}0.16 \\
\mathrm{~h}\end{array}$ & 0.02 & 1.02 & 1.44 & $\begin{array}{l}0.17 \\
\mathrm{t}(\mathrm{h})\end{array}$ \\
\hline Small & -0.51 & -0.53 & -0.47 & $-4.84 * * *$ & $-5.04 * * *$ & $-4.11^{* * *}$ \\
\hline Big & -0.41 & $\begin{array}{r}-0.52 \\
\mathrm{r}\end{array}$ & -0.45 & $-3.61^{* * *}$ & $-4.89 * * *$ & $\begin{array}{l}-4.32^{* * * *} \\
\mathrm{t}(\mathrm{r})\end{array}$ \\
\hline Small & -0.82 & -0.48 & 0.16 & $-5.00 * * *$ & $-2.70^{* *}$ & 0.89 \\
\hline Big & -1.08 & $\begin{array}{r}-0.49 \\
\mathrm{c}\end{array}$ & -0.06 & $-6.13^{* * *}$ & $-2.93^{* *}$ & $\begin{array}{l}-0.35 \\
\mathrm{t}(\mathrm{c})\end{array}$ \\
\hline Small & 0.06 & 0.48 & -0.01 & 0.27 & $1.99 *$ & -0.05 \\
\hline \multirow[t]{2}{*}{ Big } & 0.11 & 0.44 & 0.19 & 0.44 & $1.79^{*}$ & 0.80 \\
\hline & & Adjusted $\mathrm{R}^{2}$ & & & & \\
\hline Small & 0.95 & 0.95 & 0.94 & & & \\
\hline $\mathrm{Big}$ & 0.93 & 0.93 & 0.93 & & & \\
\hline
\end{tabular}

This table reports the GRS and the GMM J statistics that test whether the intercepts are equal to zero. We also report the average absolute for the intercepts (ABS(a)), the average standard error for the intercepts $\left(\mathrm{SE}(\mathrm{a})\right.$ ), and the average adjusted $\mathrm{R} 2 .{ }^{* * *},{ }^{* *}$, * denote significance at the $1 \%, 5 \%$, and $10 \%$ levels, respectively. 
Table 6: Summary statistics for the CAPM, the FF3FM, and the FF5FM

\begin{tabular}{|c|c|c|c|c|}
\hline & Size an & book-to-market & Size and investment & Size and profitability \\
\hline \multicolumn{5}{|c|}{ Panel A: the CAPM } \\
\hline GRS & $4.44^{* *}$ & $(\mathrm{pval}=0.04)$ & $4.68^{* *}(\mathrm{pval}=0.03)$ & $4.67^{* *} \quad(\mathrm{pval}=0.03)$ \\
\hline J-Stat & $3.73^{*}$ & $(\mathrm{pval}=0.05)$ & $3.93^{*} \quad(\mathrm{pval}=0.05)$ & $3.92^{*} \quad(\mathrm{pval}=0.05)$ \\
\hline $\operatorname{ABS}(\mathrm{a})$ & 1.04 & & 1.08 & 1.09 \\
\hline $\mathrm{SE}(\mathrm{a})$ & 0.56 & & 0.53 & 0.54 \\
\hline Average $\mathrm{R}^{2}$ & 0.74 & & 0.76 & 0.75 \\
\hline \multicolumn{5}{|c|}{ Panel B: the FF3FM } \\
\hline GRS & 0.52 & $(\mathrm{pval}=0.47)$ & $0.63 \quad(\mathrm{pval}=0.43)$ & $(\mathrm{pval}=0.43)$ \\
\hline J-Stat & 0.25 & $(\mathrm{pval}=0.61)$ & $0.30 \quad(\mathrm{pval}=0.58)$ & $(\mathrm{pval}=0.58)$ \\
\hline $\operatorname{ABS}(\mathrm{a})$ & 0.19 & & 0.21 & 0.30 \\
\hline $\mathrm{SE}(\mathrm{a})$ & 0.31 & & 0.31 & 0.32 \\
\hline Average $\mathrm{R}^{2}$ & 0.93 & & 0.93 & 0.93 \\
\hline \multicolumn{5}{|c|}{ Panel B: the FF5FM } \\
\hline GRS & 2.09 & $(\mathrm{pval}=0.15)$ & $2.36 \quad(\mathrm{pval}=0.13)$ & $(\mathrm{pval}=0.13)$ \\
\hline J-Stat & 0.89 & $(\mathrm{pval}=0.34)$ & $1.00 \quad(\mathrm{pval}=0.32)$ & $(\mathrm{pval}=0.32)$ \\
\hline ABS(a) & 0.40 & & 0.43 & 0.43 \\
\hline $\mathrm{SE}(\mathrm{a})$ & 0.31 & & 0.30 & 0.31 \\
\hline $\mathrm{R} 2$ & 0.94 & & 0.94 & 0.94 \\
\hline
\end{tabular}

This table reports the GRS and the GMM $J$ statistics that test whether the intercepts are equal to zero. We also report the average absolute for the intercepts (ABS(a)), the average standard error for the intercepts ( $\mathrm{SE}(\mathrm{a}))$, and the average adjusted $\mathrm{R} 2$. $^{* * *}$, **, * denote significance at the $1 \%, 5 \%$, and $10 \%$ levels, respectively.

4.5 Investigating the HML redundancy

This section investigates whether the HML factor is redundant in the FF5FM in the Shanghai exchange market. We test the performance of a fourfactor model defined as follows:

$\mathrm{R}_{i}(\mathrm{t})=\mathrm{a}_{i}+\mathrm{b}_{i}\left(\mathrm{R}_{m}(\mathrm{t})-\mathrm{R}_{f}(\mathrm{t})\right)+\mathrm{s}_{i} \mathrm{SMB}(\mathrm{t})+\mathrm{p}_{i} \mathrm{RMW}(\mathrm{t})+\mathrm{l}_{i} \mathrm{CMA}(\mathrm{t})+\mathrm{e}_{i}(\mathrm{t})$

Where $\mathrm{R}_{i}(\mathrm{t}), \mathrm{R}_{m}(\mathrm{t}), \mathrm{R}_{f}(\mathrm{t}), \mathrm{SMB}, \mathrm{RMW}$, and CMA are defined in the methodology and data section.

Similar to the previous section, we report the GRS and the GMM J statistics, along with the average adjusted $\mathrm{R}^{2}$, the average absolute of the intercepts, and the average standard error of the intercepts. Table 7 presents the details. Both the GRS and the GMM statistics show that the four-factor model outperforms the five-factor model. This result confirms the findings of Fama and French (2015) and suggests that replacing HML with RMW and CMA improves the description of average returns in the Shanghai equity market. Moreover, compared to the FF3FM, the average absolute values of the intercepts for the four factor model are lower than those of the FF3FM (except for the size/bookto-market portfolios), which means that the four factor is better in explaining the cross section of average stock returns. 
Table 7: Summary statistics for the four-factor model

\begin{tabular}{lllllll}
\hline Four-factor model & \multicolumn{2}{l}{ Size and book-to-market } & \multicolumn{2}{l}{ Size and investment } & \multicolumn{2}{l}{ Size and profitability } \\
\hline GRS & 0.18 & $($ pval=0.67) & $0.24 \quad($ pval=0.62) & 0.24 & $($ pval=0.62) \\
J-Stat & $0.10 \quad($ pval=0.75) & $0.14 \quad($ pval $=0.71)$ & 0.14 & $($ pval=0.71 $)$ \\
ABS(a) & 0.24 & & 0.17 & & 0.15 & \\
SE(a) & 0.37 & & 0.33 & 0.34 & \\
Average R ${ }^{2}$ & 0.91 & 0.92 & 0.92 & \\
\hline
\end{tabular}

This table reports the GRS and the GMM J statistics that test whether the intercepts are equal to zero. We also report the average absolute for the intercepts (ABS(a)), the average standard error for the intercepts ( $\mathrm{SE}(\mathrm{a})$ ), and the average adjusted $\mathrm{R} 2 .{ }^{* * *}$, **, * denote significance at the $1 \%, 5 \%$, and $10 \%$ levels, respectively.

\section{Conclusion}

In the last few years, there has been a growing interest in finding a better asset-pricing model. To achieve this goal, we evaluate and compare three multifactor models, the CAPM, the three-factor model, and the five-factor model in the Shanghai equity market during the period January 2011 to December 2016. We investigate the explanatory power of the market, size, value, investment, and profitability factors in describing average stock returns.

Our results show that the market factor alone is unable to explain all the variations in average stock returns. Adding the size and value factors generates a significant improvement in describing average stock returns and confirms the superiority of the three-factor model over the CAPM. However, the five-factor model does not achieve the results we expected. The profitability factor is mostly significant for all the portfolios but the investment factor is unable to explain the variations in average returns. This finding is in line with the results of Lin (2017) and Guo et al (2017) who document a weak investment pattern in the Chinese market.

Compared with the three-factor model, the five-factor model does not perform well on the Shanghai stock market. This result contradicts the findings of Fama and French $(2015,2017)$, Lin (2017) and Guo et al (2017), concerning the superiority of the five-factor model. However, regarding the redundancy of the value factor, our results are in line with those reported by Fama and French (2015). Moreover, the five-factor model without HML seems to outperform the five-factor model, which is surprising.

In this study, we used local versions of the factor pricing models, which implies that our results are only relevant to the Chinese stock market. Therefore, generalising our findings to other markets would be irrational. Fama and French (2017) showed that asset pricing in the four international regions (North America, Europe, Asia Pacific, Japan) does not conform to a global version of the FF5FM. The use of a global model depends on the level of global market integration. One possible approach would be using regional factors related to specific regions in which market integration can be plausible. 
Summing up the results, it can be concluded that the best asset-pricing model for the Shanghai equity market is the five-factor model without HML. However, this model is still unable to capture all the time-variations in average returns. A possible avenue for future work is to consider macroeconomic variables or country specific parameters related to China in explaining the average stock returns. Clearly, more research is still necessary before obtaining an efficient model for pricing Chinese equities.

\section{References}

1. Aharoni, G., Grundy, B., \& Zeng, Q. (2013). Stock returns and the Miller Modigliani valuation formula: Revisiting the Fama French analysis. Journal of Financial Economics, 110, 347-357.

2. Banz, R. W. (1981). The relationship between return and market value of common stocks. Journal of Financial Economics, 9, 3-18.

3. Bartholdy, J., \& Peare, P. (2005). Estimation of expected return: CAPM vs. Fama and French. International Review of Financial Analysis, 14, 407-427.

4. Basu, S. (1983). The relationship between earnings' yield, market value and return for NYSE common stocks: Further evidence. Journal of Financial Economics, 12, 129-156.

5. Chui, A. C., \& Wei, K. J. (1998). Book-to-market, firm size, and the turn-of-the-year effect: Evidence from Pacific-Basin emerging markets. Pacific-Basin Finance Journal, 6(34), 275-293.

6. Cochrane, J. H. (2005). Asset Pricing. vol. 1. New Jersey: Princeton University Press.

7. Drew, M., \& Veeraraghavan, M. (2001). Explaining the cross-section of stock returns in the Asian region. International Quarterly Journal of Finance, 205-222.

8. Drew, M., \& Veeraraghavan, M. (2002). Idiosyncratic volatility and security returns: evidence from the Asian region. International Quarterly Journal of Finance, 2(1-4), 1-14.

9. Fama, E. F., \&French, K. R. (1992). The crosssection of expected stock returns. The Journal of Finance, 47(2), 427-465.

10. Fama, E. F., \& French, K. R. (1993). Common risk factors in the returns on stocks and bonds. Journal of Financial Economics, 33, 3-56.

11. Fama, E. F., \& French, K. R. (1996). Multifactor explanations of asset pricing anomalies. The Journal of Finance, 51, 55-84.

12. Fama, E. F., \& French, K. R. (2008). Dissecting anomalies. The Journal of Finance, 63, 1653-1678.

13. Fama, E. F., \& French, K. R. (2015). A five-factor asset pricing model. Journal of Financial Economics, 1-22.

14. Fama, E. F., \& French, K. R. (2017). International tests of a five-factor asset pricing model. Journal of Financial Economics, 123, 441-463.

15. Gibbons, M. R., Ross, S. A., \& Shanken, J. (1989). A test of the efficiency of a given portfolio. Econometrica: Journal of the Econometric Society, 1121-1152.

16. Gray, P., \& Johnson, J. (2011). The relationship between asset growth and the crosssection of stock returns. Journal of Banking \& Finance, 35, 670-680.

17. Griffin, J. M., \& Lemmon, M. L. (2002). Book-to-market equity, distress risk, and stock returns. The Journal of Finance, 57, 2317-2336.

18. Guo, B., Zhang, W., Zhang, Y., \& Zhang, H. (2017). The five-factor asset pricing model tests for the Chinese stock market. Pacific-Basin Finance Journal, 43, 84-106.

19. Haugen, R. A., \& Baker, N. L. (1996). Commonality in the determinants of expected stock returns. Journal of Financial Economics, 41, 401-439.

20. Hou, K., Xue, C., \& Zhang, L. (2015). Digesting anomalies: An investment approach. The Review of Financial Studies, 28, 650-705.

21. Kubota, K., \& Takehara, H. (2017). Does the Fama and French Five-Factor Model Work Well in Japan? International Review of Finance,137-146.

22. Lakonishok, J., Shleifer, A., \& Vishny, R. W. (1994). Contrarian investment, extrapolation, and risk. The Journal of Finance, 49, 1541-1578. 
23. Liew, J., \& Vassalou, M. (2000). Can book-to-market, size and momentum be risk factors that predict economic growth?. Journal of Financial Economics, 57, 221-245.

24. Lin, Q. (2017). Noisy prices and the Fama-French five-factor asset pricing model in China. Emerging Markets Review, 31, 141-163.

25. Lintner, J. (1965). Security prices, risk, and maximal gains from diversification. The Journal of Finance, 20, 587-615.

26. MacKinlay, A. C., \& Richardson, M. P. (1991). Using generalized method of moments to test mean-variance efficiency. The Journal of Finance, 46, 511-527.

27. Mossin, J. (1966). Equilibrium in a capital asset market. Econometrica: Journal of the econometric society, 768-783.

28. Nichol, E., \& Dowling, M. (2014). Profitability and investment factors for UK asset pricing models. Economics Letters, 125, 364-366.

29. Novy-Marx, R. (2013). The other side of value: The gross profitability premium. Journal of Financial Economics, 108, 1-28.

30. Sharpe, W. F. (1964). Capital asset prices: A theory of market equilibrium under conditions of risk. The Journal of Finance, 19, 425-442.

31. Titman, S., Wei, K. J., \& Xie, F. (2004). Capital investments and stock returns. Journal of financial and Quantitative Analysis, 39, 677-700.

32. Xie, S., \& Qu, Q. (2016). The three-factor model and size and value premiums in china's stock market. Emerging Markets Finance and Trade, 52, 1092-1105.

33. Zaremba, A., \& Czapkiewicz, A. (2017). Digesting anomalies in emerging European markets: a comparison of factor pricing models. Emerging Markets Review, 31, 1-15. 